\title{
Multinucleated Giant Cells Polymorphism in Epulis
}

\author{
Adina Bianca BOŞCA ${ }^{1}$, Aranka ILEA ${ }^{1}$, Alina Simona ŞOVREA ${ }^{1}$, Anne Marie CONSTANTIN ${ }^{1}$, Flavia \\ RUXANDA ${ }^{2}$, V. RUS ${ }^{2 *}$, Cristian RAȚIU ${ }^{3}$, V. MICLĂUŞ ${ }^{2}$ \\ 1 "Iuliu Hatieganu" University of Medicine and Pharmacy, Cluj-Napoca, Romania \\ ${ }^{2}$ University of Agricultural Sciences and Veterinarian Medicine, Cluj-Napoca, Romania \\ ${ }^{3}$ University of Oradea, Faculty of Medicine and Pharmacy, Oradea, Romania \\ Corresponding author: vasilerus2002@yahoo.com
}

Bulletin UASVM Veterinary Medicine 72(1) / 2015,

Print ISSN 1843-5270; Electronic ISSN 1843-5378

DOI:10.15835/buasvmcn-vm: 10533

\begin{abstract} epulis.

In the present study we investigated multinucleated giant cells (MGCs) presence, density and morphology in

Histopathological examination performed on specimens excised from two patients and stained using Goldner's trichrome method revealed MGCs present in the entire epulis mass, with variable density in different areas separated by connective tissue trabeculae. Cells in early formation stages had relatively small size and contained three to five nuclei. Active cells were large, with an acidophilic cytoplasm and contained 35-40 euchromatic nuclei and phagocytic material; in hemorrhagic and necrotic areas, cells displayed abnormal shape, tending to incorporate the local debris. Cells showing different degrees of apoptosis had pyknotic nuclei, and condensed, deep acidophilic cytoplasm.
\end{abstract}

These findings suggest that, within the epulis, MGCs' distinct polymorphism regarding the size, shape, and the cytoplasmic and nuclear aspect is due to their different evolving and functional stages.

Keywords: epulis, gingiva, multinucleated giant cells.

\section{INTRODUCTION}

The giant cell epulis, also termed peripheral giant cell granuloma, is a relatively common reactive lesion of the oral cavity which occurs as a consequence of local trauma or chronic irritation; it is localized on the gingiva, in close relationship to the teeth (Cotran et al., 1989).

Epulis is not a neoplasm, but an unusual pattern of chronic inflammation, referred to as granulomatous inflammation (Cotran et al., 1989). The macrophage is a central figure in chronic inflammation because of the great number of biologically active products it can produce (Adams et al., 1988). Other types of cells present in chronic inflammation are lymphocytes, plasma cells, eosinophils, and mast cells (Cotran et al., 1989).

Histologically, the characteristic feature of granulomatous inflammations is the presence of modified macrophages which are called epithelioid cells; these cells are derived from the monocyte/ macrophage lineage (Cotran et al., 1989). In response to various foreign bodies, epithelioid cells fuse and give rise to multinucleated giant cells (MGCs) (Brodbeck and Anderson, 2009). These cells may achieve diameters of 40 to $50 \mu \mathrm{m}$ and may contain up to 50 nuclei (Cotran et al., 1989).

The classical example of granulomatous disease is tuberculosis, but sarcoidosis, deep fungal infections, reactions to a foreign body, brucellosis, schistosomiasis, cat-scratch disease, syphilis, and leptospirosy, all evoke this pattern (James, 2000). Two factors were proven to determine the formation of granulomas. One factor is the presence of indigestible organisms (such as tubercle bacillus) or particles (such as mineral oil, complex polysaccharides, and polymers). Additionally, experimental studies indicate that granulomatous inflammation is potentiated by or requires the presence of cell-mediated immunity to the inciting agent. CD4+ T cells and monocytes are in close contact and interact with each other. Activated CD $4+\mathrm{T}$ cells release $\gamma$-interferon $(\gamma$-IFN) 
and interleukin-4 (IL-4); consequently, the upregulation and secretion of DC-STAMP (Dendritic Cell-Specific Transmembrane Protein) by the monocytes; DC-STAMP causes the transformation of monocytes in epithelioid cells and MGCs in culture (Sakai et al., 2012).

Various phenotypes of MGCs have been described, according to the local environment and the nature of the stimulus to which the monocyte/ macrophage precursors and MGCs are responding (Brodbeck and Anderson, 2009).

Langhans giant cells (named after Theodor Langhans, a German pathologist and also known as Pirogrov-Langhans cells) are a specific type of MGCs found in granulomatous conditions (Pritchard et al., 2003). Their particular feature is the arrangement of the nuclei: a horseshoe-shaped pattern at the periphery of the cell (Litvinov and Ariel, 2005).

Although traditionally their presence was associated with tuberculosis, they are not specific for mycobacterial disease, but are found in nearly every form of granulomatous disease, regardless of pathology. Langhans cells are often present in the transbronchial lung biopsies or lymph node biopsies in patients suffering from sarcoidosis (Kern et al., 2003).

Another type of MGCs is the Touton giant cell, common for lipid-laden lesions, such as fat necrosis, xanthoma, and xanthogranulomas. In Touton giant cells the nuclei form a ring and are surrounded by a foamy cytoplasm (Alterman et al., 2008).

In epulis, MGCs are formed in the presence of large amounts of indigestible material, and are called foreign body-type giant cells, as they often conglomerate around a foreign body (Cotran et al., 1989). MGCs aggregates are separated by a scant fibroangiomatous stroma; foci of hemosiderin deposition may be present in the proximity of the lesion.

However, some aspects regarding the recognition, density and morphological aspects of MGCs in epulis remain unknown.

Our aim was to study the particular features of MGCs in epulis for a better understanding of their function and evolution.

\section{MATERIALS AND METHODS}

The intraoral examination of two patients identified lesions displaying a sessile aspect and different size, localized on the gingiva, in mechanically solicited areas.

The lesions were excised, fixed in 10\% buffered formalin, embedded in paraffin, sectioned at a $5 \mu \mathrm{m}$ thickness and stained using Goldner's trichrome method.

\section{RESULTS AND DISCUSSIONS}

Histopathological examination revealed features consistent with the giant cell epulis: an uncapsulated aggregation of MGCs and numerous epithelioid cells in a background of fibroblasts and extravasated red blood cells. Occasionally, connective tissue trabeculae containing blood vessels intersected the granuloma. The overlying epithelium had a variable thickness, and was ulcerated in some areas; when ulceration was present, the ulcer bed consisted of fibrinoid necrotic debris (Fig. 1) . In the peripheral zones, hemosiderin deposits were present (Fig. 2). Hemosiderin deposition is the consequence of prior hemorrhages or an inflammatory infiltrate secondary to mucosal ulceration (Cotran et al., 1989).

Within the trabeculae, the connective tissue stroma was densely cellular, containing abundant proliferating fibroblasts and chronic inflammatory cells; instead, MGCs were absent. The background of collagen fibers was well represented throughout the cellular connective tissue. Numerous blood vessels were dilated and exhibited stasis; interstitial hemorrhage and hemosiderin, along with inflammatory cells could also be seen (Fig. 3).

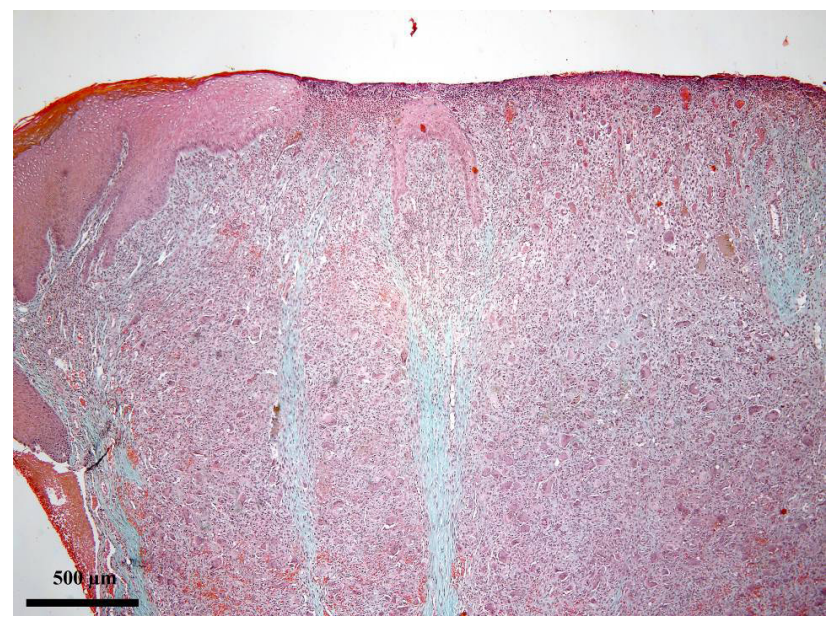

Fig. 1. Photomicrograph showing an overview of the epulis. On the surface, the epithelium was ulcerated; connective tissue trabeculae separated areas of densely packed MGCs. Goldner's trichrome. 
Within the MGCs aggregates, the cellularity was higher compared to the trabeculae; the stromal fibroblasts were rounded, resembling mesenchymal cells; the MGCs were closely associated with epithelioid cells. Epithelioid cells formed a relatively homogenous population; they had abundant, pale-pink, plump cytoplasm, resembling epithelial cells (Fig. 4) .

Numerous authors stated that MGCs result by the coalescence and fusion of the epithelioid cells (Cotran et al., 1989, McNally et al., 2011). In order to sustain this idea, on the histological sections, we also noted that the epithelioid cells showed a marked tendency to fuse with each other; the

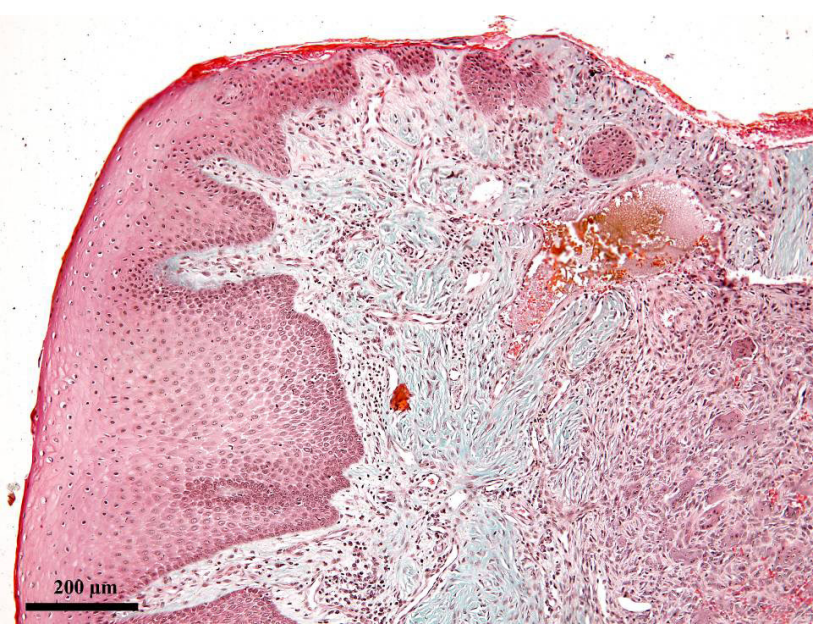

Fig.2. Hemosiderin deposition could be seen in the areas of old hemorrhage. Goldner's trichrome.

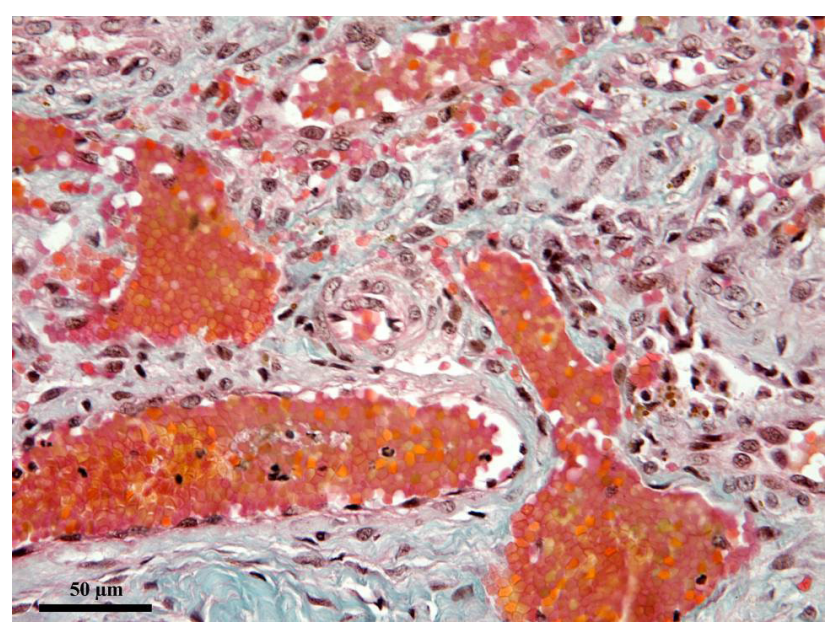

Fig. 3. Photomicrograph of the connective tissue trabeculae with dilated veins and capillaries, perivascular edema, inflammatory infiltrate, and scattered extravasated erythrocytes. Due to the venous stasis, intravascular hemolysis could be noticed. Goldner's trichrome. resulting MGCs shared the same cytoplasm and the nuclei became scattered throughout the cell. In some MGCs, the nuclei were crowded together and seemed to overlap within the mass of cytoplasm (Fig. 4, 5) .

Characteristically, MGCs showed a distinct polymorphism regarding the size, shape, and the cytoplasmic and nuclear aspect.

Cells in early formation stages had relatively small size and contained three to five nuclei. Active

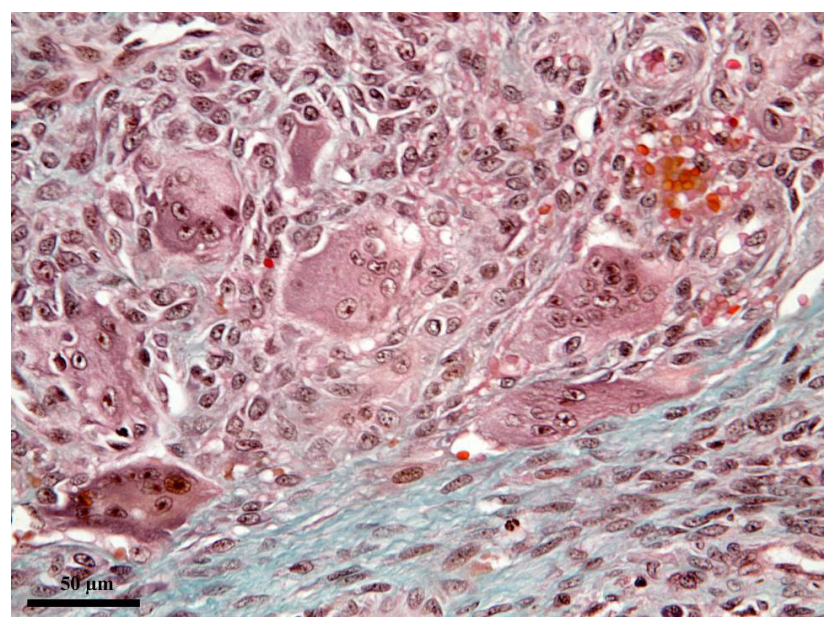

Fig. 4. Photomicrograph showing the epithelioid cells in relation to MGCs; epithelioid cells were small, polygonal to elongate, with a single round to ovalar nucleus and a moderate amount of acidophilic cytoplasm; occasionally, epithelioid cells were grouped around extravasated erithrocytes; spindle-shaped fibroblasts could be seen in the surrounding stroma. Goldner's trichrome.

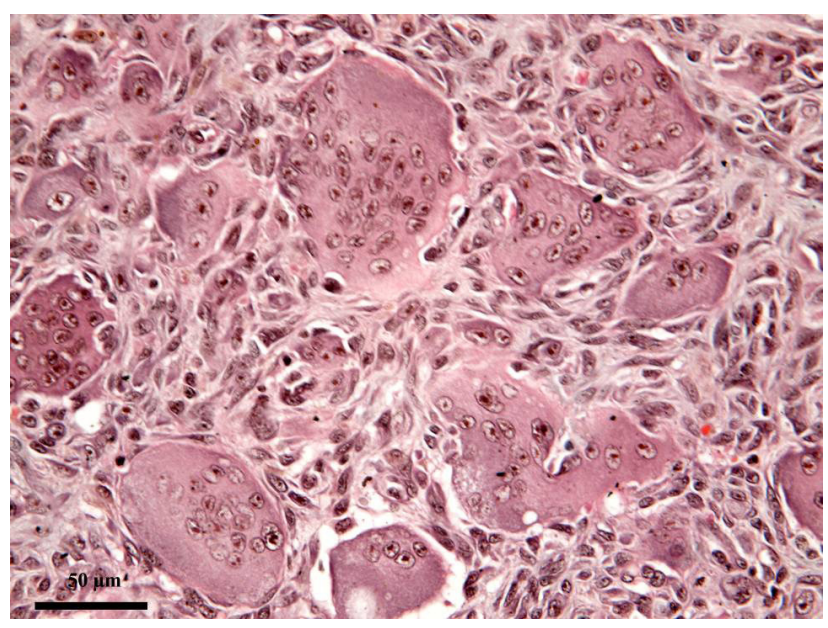

Fig. 5. Photomicrograph of the irregularly shaped MGCs, containing abundant eosinophilic cytoplasm and numerous nuclei arranged centrally in an overlapping fashion. Goldner's trichrome. 
cells were large, with an acidophilic cytoplasm and contained tens of euchromatic nuclei and phagocytic material (Fig. 6).

MGCs in resting functional state showed different degrees of apoptosis; they did not contain phagocytic material; instead they displayed the characteristic features of degenerating cells: a shrunk, condensed cytoplasm and irregular, dense nuclei (Fig. 7).

Most tumor-like hyperplasia associated with the oral cavity and the jaws have a common pathoetiology: they are all reactive lesions which appear in relation to chronic irritation or masticatory trauma (Neville et al., 2009).

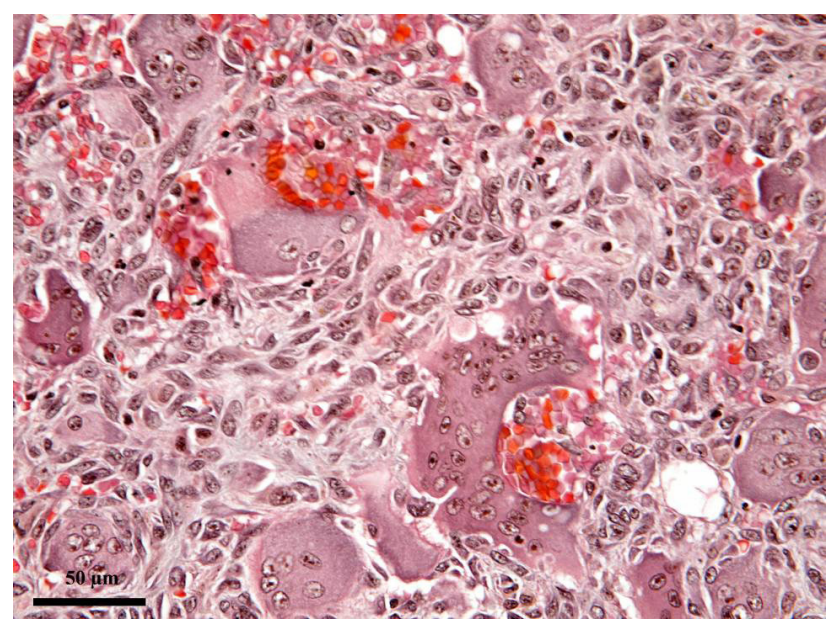

Fig. 6. Photomicrograph of active MGCs with round to oval vesicular nuclei with a single prominent central nucleolus; in hemorrhagic and necrotic areas, cells displayed abnormal shape, tending to incorporate the local debris. Goldner's trichrome.

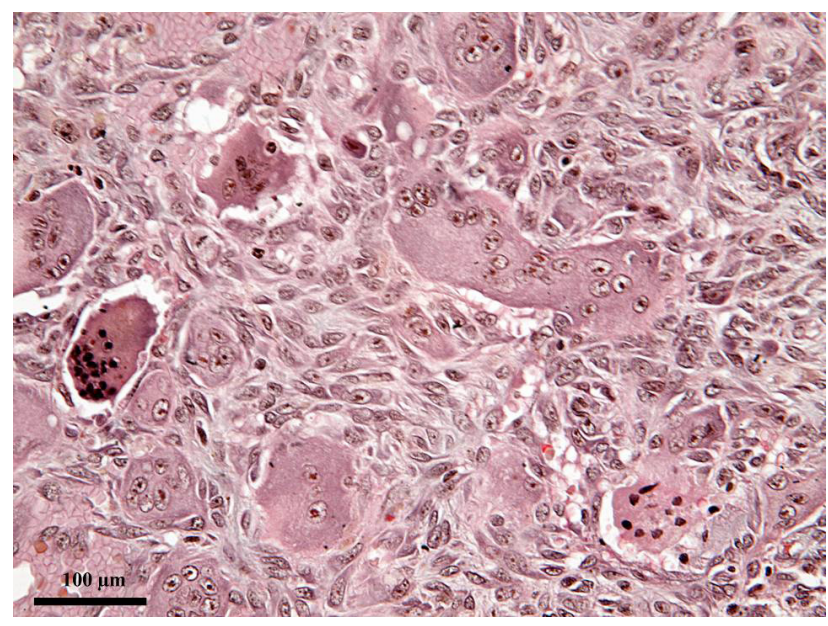

Fig. 7. Photomicrograph of degenerating, apoptotic, MGCs with pyknotic nuclei and deep acidophilic cytoplasm. Goldner's trichrome.
Histologically, these lesions show an admixture of tissue types which are compatible with epulis (i.e. the peripheral giant cell granuloma), peripheral ossifying fibroma and pyogenic granuloma. Such lesions are traditionally diagnosed according to the dominant tissue type (Naderi et al., 2012).

Peripheral ossifying fibromas usually display a combination of fibrous proliferation and mineralized masses, which may be either dystrophic calcifications, or bone-cementum-like tissue (Thompson and Wenig, 2011). Metaplastic or osteoplastic new bone formation, as well as dystrophic calcifications may be seen in epulis, especially in the zones adjacent to the alveolar bone, but the presence of the MGCs makes the difference between these two lesions (Regezi et al., 2009, Tandon et al., 2012).

In pyogenic granuloma, the major bulk of the lesion consists of a solid proliferation of endothelial cells or capillaries which forms an angiomatous tissue mass; it may be lobulated, but the amount of collagen fibers in reduced (Kamal et al., 2012).

Differentiation between epulis and extraosseuos brown tumor of hyperparathyroidism is quite challenging, because of the similar histological features: numerous giant cells with interstitial hemorrhage, and ingrowth of fibrous tissue (Etemadi et al., 2009); distinction between these lesion relies on medical history and the laboratory investigations.

Giant cell-rich osteosarcoma contain numerous osteoclast-like giant cells, admixed with undifferentiated stromal tumor cells. In some cases, these benign MGCs may obscure the malignant cells in the background (Klein and Siegal, 2006); therefore such lesion needs to be distinguished from epulis. In epulis, fibroblasts are uniformly distributed and lack dysplasia; mitotic activity of fibroblasts is common, especially in the lesions developing in children and young adults. However, in MGCs, mitoses are unusual, and, if present, should be considered a sign of sarcomatous change (Verma et al., 2011).

Epulis is a site-specific variant of granulomatous inflammation arising exclusively from periodontal ligament; actually, this lesion's denomination is quite eloquent: the term literally means "on the gingiva". But then, the microscopic characteristic feature of epulis infers from the 
other name for this lesion, i.e. peripheral giant cell granuloma.

Presence of MGCs has long been known as the key element for epulis diagnosis; still, there are many unclear aspects regarding their origin, morphology and function.

Most authors agree that in epulis, MGCs have ultrastructural and immunohistochemical features similar to osteoclasts (Flanagan et al., 1988, Neville et al., 2009, Naderi et al., 2012, Liu et al., 2003); however, there is much controversy related to MGCs origin. MGCs are assumed to arise from syncytial fusion of mononuclear precursors of bone marrow origin; other possible sources could be endothelial cells or stromal cells (Rajendran, 2006).

More and more data support the concept that MGCs are a reactionary component of the lesion and derive from mononuclear cells in the blood stream, which are recruited and differentiate only in response to certain stimuli from stromal cells (Cotran et al., 1989, El-Mofty and Osdoby, 1985, Cohen et al.1988). Therefore, the complex interrelation between the cellular components is crucial for the formation of MGCs (Liu et al., 2003).

In order to sustain this idea, recent studies using cell culture and transplantation (El-Mofty and Osdoby, 1985, Cohen et al.1988) reported that MGCs had a short life and disappeared early in culture, contrarily to the stromal cells which underwent an active proliferation.

Willing et al. demonstrated that cytokines and differential factors secreted by stromal cells act as monocyte chemoattractants and are essential for osteoclast differentiation; these molecules, including monocyte chemoattractant protein-1 (MCP1), macrophage-colony stimulating factor (M-CSF), and osteoclast differentiation factor (ODF) stimulate blood monocyte migration into granuloma and their coalescence into osteoclastlike, MGCs (Willing et al., 2001).

Moreover, Abe et al. identified a protein family which has disintegrin and metalloproteinase domains; these proteins, including Meltrinalpha, beta and gamma, are implicated in fusion of mononuclear precursors and formation of multinucleated cells, such as MGCs and osteoclasts (Abe et al.,1999).

Liu B. et al. performed enzyme histochemical and immunohistochemical studies on various giant-cell containing tumor-like lesions of the oral cavity and the jaws and demonstrated that there were two categories of stromal cells. A fraction of mononuclear stromal cells might be were positive for TRAP (tartarate-resistant acid phosphatase) and could be the MGCs precursors; these stromal cells also expressed carbonic anhydrase II (CA II), vacuolar $\mathrm{H}+$-ATPase (V-ATPase), Cathepsin $\mathrm{K}$, and CD68 and matrix metalloproteinases-9 (MMP-9). The other type of stromal cells, the spindle-shaped cells, was positive for proliferating cell nuclear antigen (PCNA) (Liu et al., 2003)

An interesting aspect is that in some cases, MGCs exhibited surface receptors for estrogen; these findings led to the speculation that some lesions may be responsive to hormonal influences (Gandara-Rey et al., 2002)

Coexistence of active and apoptotic cells within the epulis suggests that MGCs have a unidirectional life cycle; MGCs arise from the fusion of epithelioid cells, they reach their maximal functional potential, and then degenerate; eventually, aged MGCs are gradually eliminated and permanently replaced by newly formed cells.

\section{CONCLUSIONS}

Multinucleated giant cells in epulis are active cells, responsible for eliminating foreign bodies and cell debris by phagocytosis. Most probably, their polymorphism is due to the fact that giant cells are in different evolving and functional stages.

\section{REFERENCES}

1. Abe E, Mocharla H, Yamate T, Taguchi Y. Monolages SC (1999). Meltrin-alpha, a fusion protein involved in multinucleated giant cell and osteoclast formation. Calcif Tissue 64:508-15. 2. Adams DO, Hamilton TA (1988). Phagocytic cells. Cytotoxic activities of macrophages. In : Gallin JI et al. (eds.). Inflammation: Basic Principles and Clinical Correlates. New York, Raven Press, 471.

2. Aterman K, Remmele W, Smith M Karl (1988). Touton and his "xanthelasmatic giant cell." A selective review of multinucleated giant cells. Am J Dermatopathol 10(3):25769.

3. Brodbeck WG, Anderson JM (2009). Giant cell formation and function. Curr Opin Hematol. Jan 16(1):53-7.

4. Cohen MA, Grossman ES, Thompson SH (1988). Features of central giant cell granuloma of the jaws xenografted in nude mice. Oral Surg Oral Med Oral Pathol 66:209.

5. Cotran RS, Kumar V, Robbins SL (1989). Inflammation and Repair. In : Robbins' Pathologic Basis of Disease. $4^{\text {th }}$ Edition, W.B. Saunders International Edition, 66-68, 821. 
6. El-Mofty SK, Osdoby P (1985). Growth behaviour and lineage of isolated and cultured cells derived from giant cell granuloma of the mandible. J Oral Pathol 14:539-52.

7. Etemadi J, Mortazavi-Khosrowshahi M, Ardalan MR, Esmaili H, Javadrashid R, Shoja MM. (2009). Brown tumor of hyperparathyroidism masquerading as central giant cell granuloma in a renal transplant recipient: a case report. Transplant Proc 41(7):2920-2.

8. Flanagan AM, Tinkler SMB, Horton MA, Williams MD, Chambers DJ. (1988). The multinucleated giant cell granulomas of the jaws are osteoclasts. Cancer 62:113945.

9. Gandara-Rey JM, Pacheo Martina Carneriro JL, GandaraVila $\mathrm{P}$ et al. (2002). Peripheral giant-cell granuloma: Review of 13 cases. Med Oral 7:254-59.

10. James D G A (2000). Clinicopathological classification of granulomatous disorders. Postgrad Med J 76:457-465.

11. Kamal R, Dahiya P, Puri A (2012). Oral pyogenic granuloma: Various concepts of etiopathogenesis. J Oral Maxillofac Pathol 16(1):79-82.

12. Kern I, Kecelj P, Kosnik M, Mermolja M (2003). Multinucleated giant cells in bronchoalveolar lavage. Acta Cytol 47(3):426-30.

13. Klein MJ, Siegal GP. (2006). Osteosarcoma: anatomic and histologic variants. Am J Clin Pathol 125(4):555-81.

14. Litvinov AV, Ariél' BM (2005). Historical reference: giant multinuclear cells in tubercular granuloma. Probl Tuberk Bolezn Legk 11:59-61.

15. Liu B, Yu SF, Li TJ (2003). Multinucleated giant cells in various forms of giant cell containing lesions of the jaws express features of osteoclasts. J Oral Pathol Med 32(6):367-75.

16. McNally AK, Anderson JM (2011). Macrophage fusion and multinucleated giant cells of inflammation. Adv Exp Med Biol 713:97-111.
17. Naderi NJ, Eshghyar N, Esfehanian $\mathrm{H}$ (2012). Reactive lesions of the oral cavity: A retrospective study on 2068 cases. Dent Res J (Isfahan) 9(3):251-5.

18. Neville BW, Damm DD, Allen CM, Bouquot JE. (2009). Oral and maxillofacial pathology. 3rd ed. China: Saunders, 510-23.

19. Pritchard J, Foley P, Wong H (2003). Langerhans and Langhans: what's misleading in a name?. Lancet 362(9387):922.

20. Rajendran R. (2006). Benign and Malignant Tumors of the Oral Cavity. In : Rajendran R, Sivapathsundaram B (eds.). Shafer's Textbook of Oral Pathology 5th ed. New Delhi: Elsevier, 113-308.

21. Regezi JA, Sciubba JJ, Jordan RCK (2009). Red-Blue lesions. In : Regezi JA, Sciubba JJ, Jordan RCK (eds.) Oral Pathology. Clinical Pathologic Correlations 5th ed. St. Louis: Saunders, 107-25.

22. Sakai H, Okafuji I, Nishikomori R, et al. (2012). The CD40CD $40 \mathrm{~L}$ axis and IFN- $\gamma$ play critical roles in Langhans giant cell formation. Int Immunol 24 (1): 5-15.

23. Tandon PN, Gupta SK, Gupta DS, Jurel SK, Saraswat A. (2012). Peripheral giant cell granuloma. Contemp Clin Dent 3(Suppl 1):S118-21.

24. Thompson LD and Wenig BM. (2011). Diagnostic Pathology: Head and Neck. Lippincott Williams \& Wilkins, 4:66-67

25. Verma RK, Gupta G, Bal A, Yadav J (2011). Primary giant cell rich osteosarcoma of maxilla: an unusual case report. J Maxillofac Oral Surg 10(2):159-62.

26. Willing M, Engels C, Jesse N, Werner M, Delling G, Kaiser E (2001). The nature of giant cell tumor of bone. J Cancer Res Clin Oncol 127:467-74. 